\title{
Combustion Modeling of Aluminum Incorporated in Low-Explosive Formulations such as Solid Propellants
}

\author{
Rene Francisco Boschi Gonçalves, Koshun Iha1, José Atílio Fritz Fidel Rocco
}

\begin{abstract}
Aluminum that is incorporated in an energetic material such as a propellant plays a significant role in the combustion process by means of stabilization with regard to the burning and generation of additional energy. The use of simulation softwares to model the combustion mechanism and kinetic parameters of the elementary reactions that compose the oxidation were used as the pressure variation of the combustion chamber of a rocket motor conditions. The behavior of the molar fraction of the chemical species during the combustion and its posterior stabilization were observed. The systems submitted to higher pressures tend to stabilize more rapidly, according to the greater chemical speed of the elementary reactions.
\end{abstract}

KEYWORDS: Aluminum, Combustion simulation, Chemkin.

\section{INTRODUCTION}

\section{FLAME STRUCTURE OF A COMPOSITE SOLID PROPELLANT GRAIN}

Most of the current available knowledge on chemical aspects involving combustion of composite solid propellants regards studies of flame structures like, for example, the spatial distribution of temperatures and concentrations of chemical species involved in the combustion. Data analysis of the flame structure can provide information on the composition (generated from reactions in the condensed phase) of the products that have originated from thermal decomposition on the burning surface of a solid propellant grain. Therefore, it is possible to identify the reactions that occur in the condensed phase, in addition to the reaction pathways involved. Furthermore, the chemical structure of the flame provides information on the mechanism and kinetics of the chemical reactions in the gas phase and subsequent processing of the products, with reactions considered responsible for the generation of heat from the gas phase. The development of combustion models for solid propellant formulations requires information on the reactions involved, in both the condensed and gas phases of the process. Without this information, it is impossible to develop a model that is able to predict actual parameters such as burning rate and other ballistic characteristics, which are intrinsic to the material considered Korobeinichev et al., 1974.

In the last four decades, studies have been performed in order to meet the ever more comprehensive process of energetic material combustion in special formulations of solid

\footnotetext{
1.Instituto Tecnológico de Aeronáutica - São José dos Campos/SP - Brazil

Author for correspondence: Rene Francisco Boschi Gonçalves | Departamento de Química, Instituto Tecnológico de Aeronáutica | Praça Mal. Eduardo Gomes, 50 Vila das Acácias | CEP 12.228-900 São José dos Campos/SP - Brazil | Email: renefbg@gmail.com

Received: 07/03/13 | Accepted: 12/06/13
} 
propellants (Barrere, 1968; Williams et al., 1969; Kuo et al., 1984; Chiaverini et al., 1999; Gonçalves et al., 2009). However, the complete combustion of this process is unknown because, in practice, it involves many parameters such as steady-state combustion, erosive burning, combustion in transient state (ignition and combustion instabilities), and combustion of finely divided metal particles such as aluminum or boron (incorporated in the material) (Davenas, 2003).

\section{BURNING INSTABILITIES}

Currently, most of the research done in propulsion of solid propellant rocket engines (SPRE) is directed to the understanding of a phenomenon that is widely known as "burning instability." This phenomenon directly affects the burning of such material due to the resonance characteristic of the combustion process. A great mass of information is obtained pertaining to flame structure, heat-release mechanisms, combustion response in acoustical terms (Shusser et al., 2000), and the development of the flow that is established from burning. The term "combustion response" refers to the response given by lowamplitude linear frequency caused by the combustion of solid propellants (harmonic oscillations in the combustion chamber pressure during combustion) (Brewster, 2000). However, despite these contributions, the existing burning models provide limited information about the fluid dynamics behavior in the regions where oscillations are observed in turbulent flow of gases inside the combustion chamber of the SPRE (Flandro et al., 2000).

In the 1960s, when most research in this area was directed to formulations of composites based on ammonium perchlorate (AP), Summerfield et al., (1966) identified the mechanism by which this process occurred and proposed a burning model named granular diffusive flame. In this model, based on the assumption that both the fuel and the oxidant are converted from solid to gas on the burning surface and are diffused together forming the flame front, an understanding of the composite combustion process as a whole was initiated. However, parameters such as large variations in the burning velocity of solid propellants as a function of the pressure in the combustion chamber, distribution of the granulometric profile of the loads (AP, aluminum, and Al-additives), and the concentration of such fillers in the composite formulated required models broader than initially proposed by Summerfield et al., (1966).
In the early 1970s, Beckstead et al., (1970) presented a model called multiple flame, which was based on a complex interaction between the flame generated from the thermal decomposition of the oxidant and two other diffusive flames immediately above the interface between the "binder" (organic part of the propellant) and the oxidant (material responsible for supplying oxygen to the combustion process). This phenomenological interpretation of the combustion process of solid propellant was used for many years to explain the burning behavior of composites based on AP, and also in double-based ones (nitroglycerin/nitrocellulose). Apparently, the diffusive flame generated from the thermal decomposition of AP is dominant in the mechanism present in Beckstead's model and is related to the manner in which the AP decomposes, generating a large amount of chemical species derived from chlorine. These species (extremely reactive) allow a fast increase of the flame temperature and maintain the stability of the whole combustion process of the composite. To date, this phenomenological interpretation of Beckstead et al., (1970) remains valid.

The use of computer packages for burning simulation of energetic materials, with an emphasis on aluminum oxidation, is the focus of this work.

\section{METHODOLOGY}

The combustion modeling of solid propellant formulations can be performed through computer simulation using the software Chemkin (Aurora reactor, for the current work), developed by "Sandia National Laboratories, Livermore, CA" (Coltrin et al., 1991). This software is aimed at solving complex problems involving chemical kinetics using complex reaction pathways. The program's architecture offers information on specific problems, as well as models of independent problems and some packages with preselected reaction models that take into account the equations of mass, energy, chemical species and, in some cases, momentum conservation. When solving a specific problem, there is a need to identify the chemical species involved in the process (combustion) and its properties, such as enthalpy $(\mathrm{H})$, entropy $(\mathrm{S})$ and heat capacity at constant pressure and volume $(\mathrm{Cp}, \mathrm{Cv})$ beyond the reaction pathways and reaction rates involved. 


\section{COMBUSTION OF AN ALUMINUM PARTICLE OXIDIZED BY AIR}

Computer simulations provide a very convenient support relative to understand the physics of combustion of many chemical species, particularly aluminium, in processes which take into account the growth of the oxide layer that covers its surface. If the modeling is sufficiently complete, it is possible to obtain results (data) leading to the burning rates involved in aluminum combustion.

Initial simulations of aluminum combustion (drops) were performed by Liang and Beckstead (1998). This two-dimensional model takes into account effects such as forced convection, radiation, growth of the oxide layer, transport properties variation and an extended condensation zone. The model considers a reaction mechanism involving nine steps, including two surface reactions, three gas-phase reactions, a dissociation reaction of the molten $\mathrm{Al}_{2} \mathrm{O}_{3}$, and three condensation reactions. In order to study the combustion of aluminum (drops) in an environment, for example, in the case of a rocket engine, these researchers (Liang and Beckstead, 1998) modified the kinetic model to consider the reaction of aluminum with $\mathrm{H}_{2} \mathrm{O}$ and $\mathrm{CO}_{2}$, as well as condensation reactions involving each of these oxidizers. Simultaneously, the thermodynamic properties were adjusted to follow changes in pressure.

In this modeling, the process of aluminum combustion in vapor phase occurs in a homogeneous reactor where it is considered that throughout the control volume there is a perfectly homogenous mixture between fuel and oxidant chemical species (PSR - Perfect Stirred Reactor). The reaction mechanism for the oxidation of aluminum in the air consists of nine elementary reactions that are described next:

$$
\begin{aligned}
& \mathrm{Al}+\mathrm{O}_{2}=\mathrm{AlO}+\mathrm{O} \\
& \mathrm{AlO}=\mathrm{Al}+\mathrm{O} \\
& \mathrm{AlO}+\mathrm{O}_{2}=\mathrm{AlO}_{2}+\mathrm{O} \\
& \mathrm{AlO}_{2}=\mathrm{AlO}+\mathrm{O} \\
& \mathrm{Al}_{2} \mathrm{O}=\mathrm{Al}+\mathrm{AlO} \\
& \mathrm{Al}_{2} \mathrm{O}_{2}=\mathrm{AlO}+\mathrm{AlO} \\
& \mathrm{Al}_{2} \mathrm{O}_{2}=\mathrm{AlO}+\mathrm{Al} \\
& \mathrm{Al}_{2} \mathrm{O}_{2}=\mathrm{Al}_{2} \mathrm{O}+\mathrm{O} \\
& \mathrm{O}_{2}+\mathrm{M}=\mathrm{O}+\mathrm{O}+\mathrm{M} \text {, where } \mathrm{M} \text { is an inert molecule. }
\end{aligned}
$$

\section{THERMAL DECOMPOSITION MODELING OF ALUMINUM}

In order to perform the thermal decomposition modeling of aluminum in a homogeneous reactor (transient state), the software Chemkin/Aurora model was utilized. In this type of reactor, the reacting species (in gaseous form) are homogeneously dispersed throughout the system volume, where the ignition subsequently occurs, resulting in an abrupt increase in temperature (due to heat release by the exothermic combustion reactions of alumina) and volume (due to high gas formation), in addition to changes in mole fractions of the chemical species considered for the modeling.

The temperature used in the simulation $\left(1700^{\circ} \mathrm{C}\right)$ resembles the observed temperature in a combustion chamber of a conventional rocket motor. Various values have been used to denote pressure, including 1, 10, 30, and 60 atmospheres, with the last value being the observed pressure in a combustion chamber of a conventional rocket motor. The mechanism used in modeling and Arrhenius data of each elementary reaction are depicted in Table 1.

Table 1. Alumina combustion mechanism.

\section{Reactions}

\begin{tabular}{|c|c|c|r|}
\hline $\mathrm{Al}+\mathrm{O}_{2}=\mathrm{AlO}+\mathrm{O}$ & $9.72 \mathrm{E} 13$ & 0.0 & 159.95 \\
\hline $\mathrm{Al}+\mathrm{O}+\mathrm{M}=\mathrm{AlO}+\mathrm{M}$ & $3.0 \mathrm{E} 17$ & -1.0 & 0.00 \\
\hline $\mathrm{AlO}+\mathrm{O}_{2}=\mathrm{OAlO}+\mathrm{O}$ & $4.62 \mathrm{E} 14$ & 0.0 & 19885.90 \\
\hline $\mathrm{Al}_{2} \mathrm{O}_{3}=\mathrm{AlOAlO}+\mathrm{O}$ & $3.0 \mathrm{E} 15$ & 0.0 & 97649.99 \\
\hline $\mathrm{Al}_{2} \mathrm{O}_{3}=\mathrm{OAlO}+\mathrm{AlO}$ & $3.0 \mathrm{E} 15$ & 0.0 & 126999.89 \\
\hline $\mathrm{AlOAlO}=\mathrm{AlO}+\mathrm{AlO}$ & $1.0 \mathrm{E} 15$ & 0.0 & 117900.00 \\
\hline $\mathrm{AlOAlO}=\mathrm{Al}+\mathrm{OAlO}$ & $1.0 \mathrm{E} 15$ & 0.0 & 148900.00 \\
\hline $\mathrm{AlOAlO}=\mathrm{AlOAl}+\mathrm{O}$ & $1.0 \mathrm{E} 15$ & 0.0 & 104249.94 \\
\hline $\mathrm{OAlO}=\mathrm{AlO}+\mathrm{O}$ & $1.0 \mathrm{E} 15$ & 0.0 & 88549.86 \\
\hline $\mathrm{AlOAl}=\mathrm{AlO}+\mathrm{Al}$ & $1.0 \mathrm{E} 15$ & 0.0 & 133199.94 \\
\hline $\mathrm{Al}=\mathrm{Al}$ & $1.0 \mathrm{E} 14$ & 0.0 & 0.00 \\
\hline $\mathrm{Al} \mathrm{O}_{3}=\mathrm{Al} \mathrm{O}_{3}$ & $1.0 \mathrm{E} 14$ & 0.0 & 0.00 \\
\hline $\mathrm{Al}+\mathrm{H}_{2} \mathrm{O}=\mathrm{H}+\mathrm{AlOH}$ & $1.14 \mathrm{E} 12$ & 0.0 & 442.80 \\
\hline $\mathrm{Al}+\mathrm{H}_{2} \mathrm{O}=\mathrm{AlO}+\mathrm{H}_{2}$ & $9.6 \mathrm{E} 13$ & 0.0 & 2868.60 \\
\hline $\mathrm{AlOH}=\mathrm{Al}+\mathrm{OH}$ & $1.0 \mathrm{E} 15$ & 0.0 & 66431.80 \\
\hline $\mathrm{AlOH}=\mathrm{AlO}+\mathrm{H}$ & $1.0 \mathrm{E} 15$ & 0.0 & 57725.20 \\
\hline
\end{tabular}




\section{RESULTS AND DISCUSSION}

The combustion simulations of alumina were performed at different pressures $(1,10,30$, and 60 atmospheres). In Fig. 1 it is possible to observe the behavior of the molar fractions of the chemical species involved in the process, according to the elapsed time of combustion from ignition, and also the system volume variation as a function of time.

The predominant chemical species in the simulation at 1 atmosphere are aluminum, gaseous oxygen, aluminum oxide, and elementary oxygen. Due to the low pressure at which the system is submitted, there is little formation of alumina and its intermediates. In this case, therefore, the predominant reaction is the capture of one of the oxygen atoms of $\mathrm{O}_{2}$ by the aluminum atom, with the formation of aluminum oxide (I) and elemental oxygen.

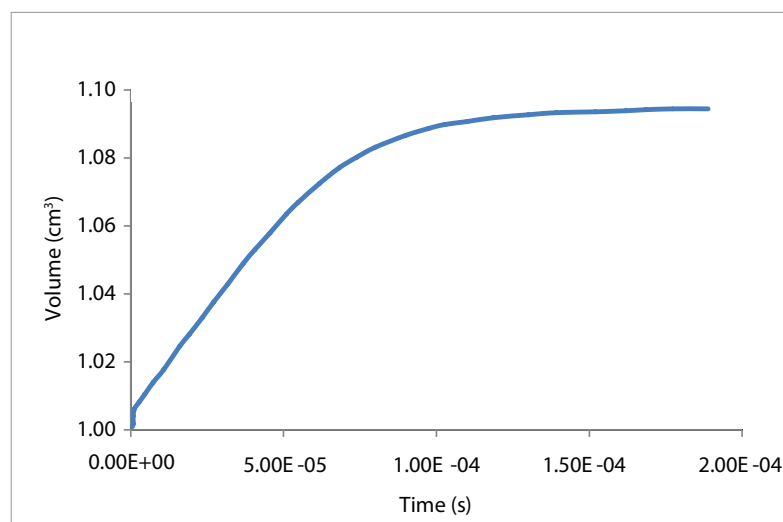

(a)

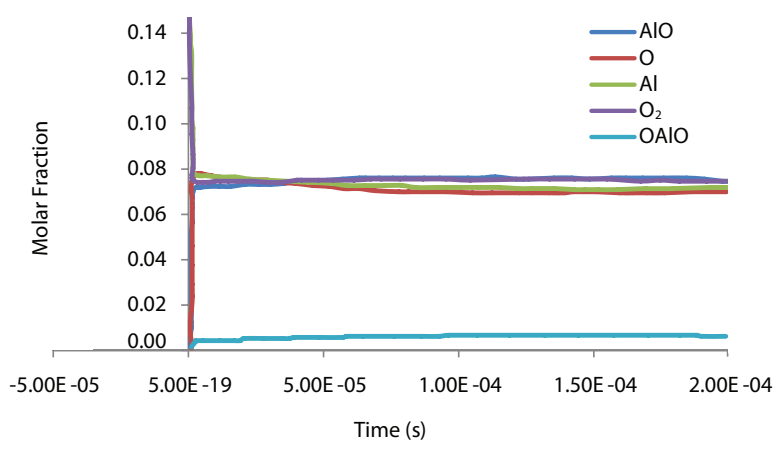

(b)

Figure 1. Volume (a) and molar fractions of the chemical species (b) versus time from ignition to the combustion process of alumina with gaseous oxygen at 1 atmosphere.
Figure 2 shows the simulation results depicting the pressure at 10 atmospheres.

In the case where the pressure is 10 atmospheres, a higher reaction rate is initially noticed due to a sudden volume increase as a result of the system ignition. The mole fractions of intermediate species suffered additions, as in this case the higher pressure enables the occurrence of all intermediate reactions present in the mechanism. However, there is still not enough time to stabilize the system considered $\left(2.10^{-4} \mathrm{~s}\right)$, residence time of chemical species in the combustion chamber in question, showing that the reaction does not occur fast enough to ensure burning stability and greater efficiency.

Figure 3 presents the combustion process at 30 atmospheres.

The speed of the process, in terms of the (volume versus time) curve slope, increased even more in this case, as there is a fast increase and stabilization of the volume, shortly after the ignition of the combustion process.

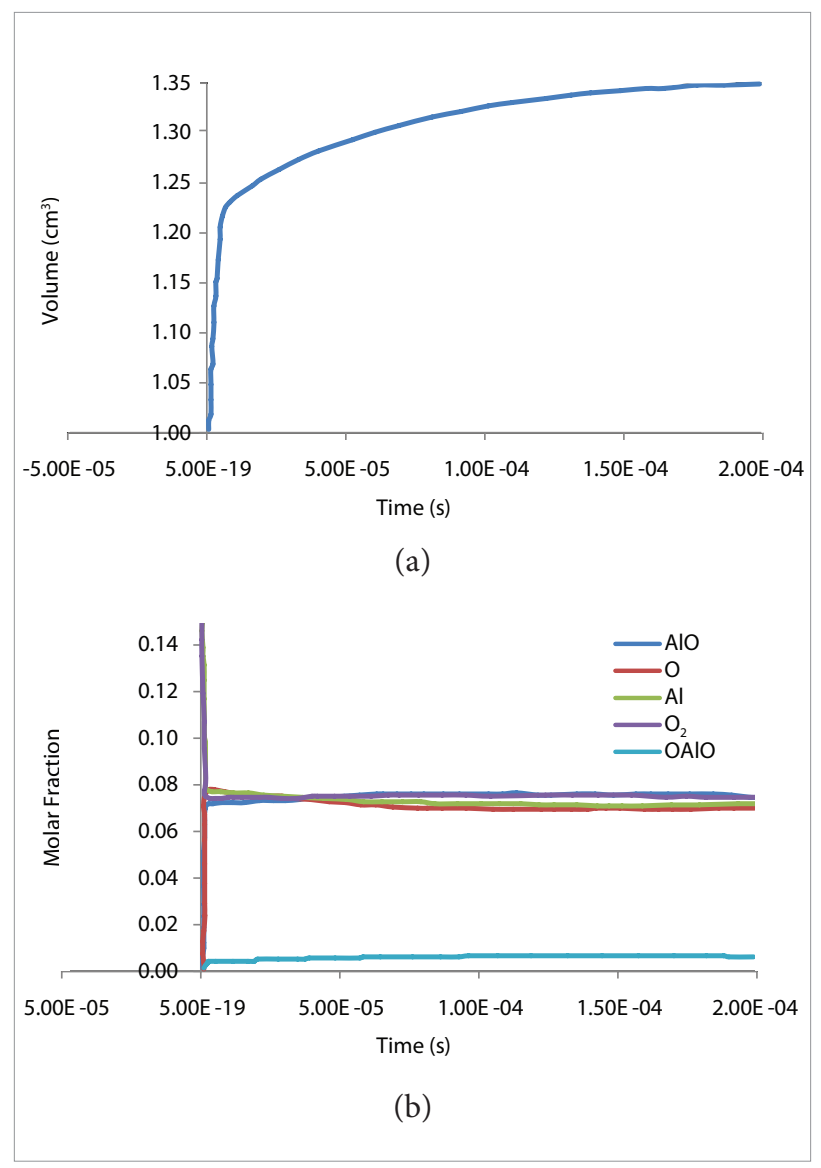

Figure 2. Volume (a) and molar fractions of the chemical species (b) versus time from ignition to the combustion process of alumina with gaseous oxygen at 10 atmospheres. 
The molar fractions of the chemical species suffered significant variations and this time the speed of the elementary reactions present in the mechanism is high enough to stabilize the system shortly after ignition. This stabilization ensures a better control of the burning process, providing stability and increasing combustion efficiency.

Another simulation was performed, with the system subjected to a pressure of 60 atmospheres, shown in Fig. 4.

The difference between the aluminum at 30 and 60 atmospheres in the combustion process is based on the speed at which the burning process stabilizes. At 60 atmospheres, the system volume increases instantaneously to its equilibrium (value greater than that achieved at lower pressures), after the ignition stimulation. In the case of chemical species, there is a mole fraction variation that is approximately its equilibrium value, which is reached almost instantly after ignition.

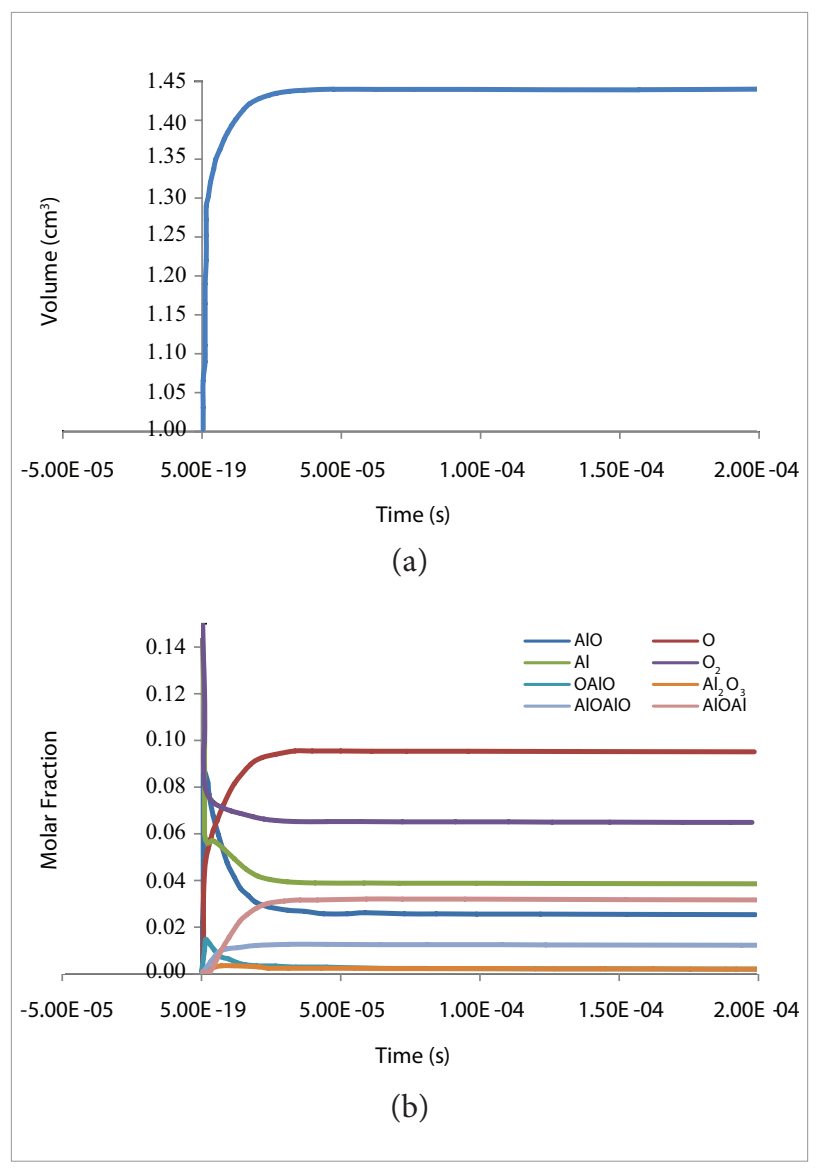

Figure 3. Volume (a) and molar fractions of the chemical species (b) versus time from ignition to the combustion process of alumina with gaseous oxygen at 30 atmospheres.

\section{CONCLUSION}

The kinetics of alumina formation from aluminum was simulated at different pressures in a condition close to the one found in a combustion chamber of a solid propellant rocket motor, not considering the reacting flow to which the system is subjected in a continuous operation. An increase in the pressure at which the reactants are subjected is a determinant in the early establishment of a steady-state, in which there is a balance between the chemical species that react and their products. It was observed that the systems subjected to greater pressures tend to stabilize faster, due to the greater chemical speed of elementary reactions present in the combustion mechanism of aluminum, enabling a greater burning stability of the material and higher efficiency.

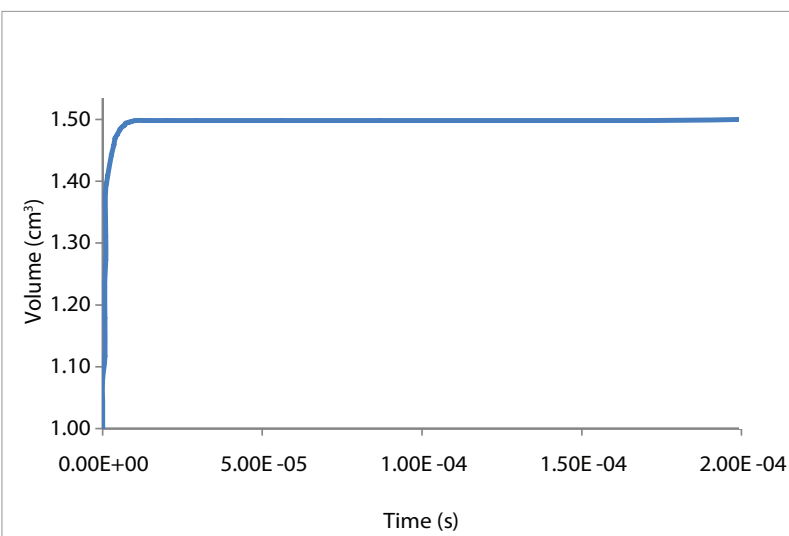

(a)

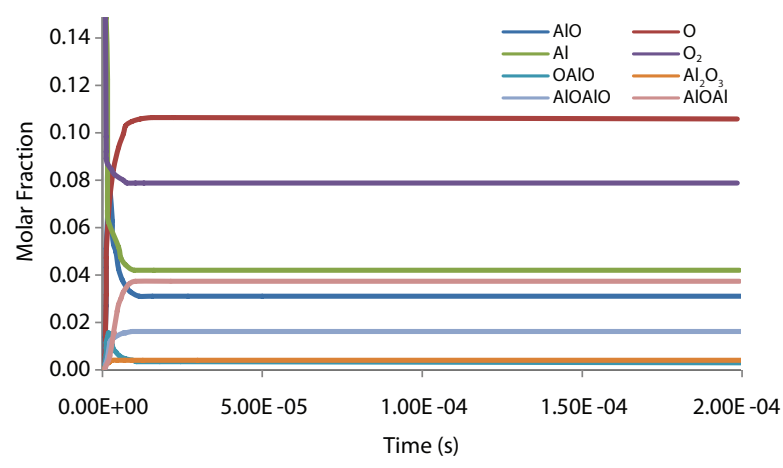

(b)

Figure 4. Volume (a) and molar fractions of the chemical species (b) versus time from ignition to the combustion process of alumina with gaseous oxygen at 60 atmospheres. 
In chemical propulsion systems, such as the SPRM, increased operating pressure in the combustion chamber leads to displacement of the equilibrium toward the products, thus increasing the yield of the reaction.

\section{ACKNOWLEDGMENTS}

The authors thank CAPES, CNPq, and FAPESP for the financial support rendered.

\section{REFERENCES}

Barrere, M., 1968, "Solid Propellant Ignition: General Consideration". Research Aerospatiale, pp. 15-28.

Beckstead, M.W., Derr, R.L. and Price, C.F., 1970, "A Model of Composite Solid Propellant Combustion Based on Multiple Flames", AIAA Journal, Vol. 8, pp. 2200-2207.

Brewster, M.Q., 2000, "Solid Propellant Combustion Response: Quasi-Steady (QSHOD) Theory Development and Validation", Progress in Astronautics and Aeronautics, AIAA, Vol. 185.

Chiaverini, M.J., Harting, G.C., Lu, Y.C., Kuo, K.K., Peretz, A., Jones, H.S., Wygle, B.S. and Arves, J.P., 1999, "Pyrolysis behavior of hybrid-rocket solid fuels under rapid heating conditions", Journal of Propulsion and Power, Vol. 6, pp. 888-895.

Coltrin, M.E., Kee, R.J., Evans, G.H., Meeks, E., Rupley, F.M. and Grcar, J.F., 1991, "A Fortran Program for Modeling One-Dimensional Rotating-Disk/Stagnation Flow Chemical Vapor Deposition Reactors", Sandia Report.

Davenas, A., 2003, "Development of Modern Solid Propellants". Journal of Propulsion And Power, Vol. 19, pp. 1108-1128.

Flandro, G.A., Cai, W. and Yang, V., 2000, "Turbulent Transport in Rocket Motor Unsteady Flowfield", Progress in Astronautics and Aeronautics, AIAA, Vol. 185.
Gonçalves, R.F.B, Rocco, J.A.F.F., Iha, K. and Machado, F.B.C., 2009, "Modelagem da combustão da dinitramida de amônio por simulação computacional", Química Nova, Vol. 32.

Korobeinichev, O.P., Anisiforov, G.I. and Tereshchenko A.G., 1974, "Study of high-temperature kinetics and mechanism of thermal decomposition of mixtures of ammonium perchlorate-polymeric binder-catalyst using the time-of-flight mass-spectrometer", 12th Aerospace Science Meeting.

Kuo, K.K., Gore, J.P. and Summerfield, M., 1984, "Transient Burning of Solid Propellant", Progress in Astronautics and Aeronautics, Vol. 90, AIAA, pp. 599-651.

Liang, Y. and Beckstead, M.W., 1998, Numerical Simulation of QuasiSteady, Single Aluminum Particle Combustion in Air, AIAA Paper 98-254.

Shusser, M., Culick, F.E.C. and Cohen, N.S., 2000, "Combustion Response of Ammonium Perchlorate", 36 th AIAA, SAE, ASME and ASEE Joint Propulsion Conference, Huntsville, A.L.

Summerfield, M., Parker, K.H. and Most, W.J., 1966, "The Ignition Transient in Solid Propellant Rocket Motor", Princeton University, Princeton, N.J., Aerospace and Mechanical Sciences Report 769.

Williams, F.A., Barrere, M. and Hung, N.C., 1969, "Fundamental Aspects of Solid Propellant Rockets", AGARDograph 116, Technivision Services, pp. 510-531, Slough, England. 